\title{
Laser-Induced Photoreaction of Bis(4-nitrophenyl) Disulfide on Copper Revealed by Surface-Enhanced Raman Scattering
}

\author{
Kuan Soo Shin \\ Department of Chemistry, Soongsil Lnwersity, Seoul 156-743, Korea. E-mail: kshinassu.ac.kr \\ Received Wovember 13, 2008, Accepted November 20, 2008
}

Key Words: Surface-enhanced Raman scattering. Photoreaction. Copper substrate. Biș(4-nitrophenyl) disulfide

Noble metallic nanostructures exhibit a phenomenon known as surface-enhanced Raman scattering (SERS) in which the Raman scattering cross sections are dramatically enhanced for molecules adsorbed thereon. ${ }^{1-4}$ Although the exact mechanism of SERS is still a matter of controversy. it is generally accepted that two enhancement mechanisms. one a long-range electromagnetic (EM) effect and the other a short-range chemical (CHEM) effect, are simultaneously operative. Both mechanisms suggest the possibility of the enhanced absorption and enhanced photochemistry for surface-adsorbed molecules.

Direct observation of a surface-enhanced photochemical reaction has been reported. Aromatic sulfides such as bencyl phenyl sulfide and dibenzyl sulfide adsorbed on silver undergo surface reactions involving facile cleavage of $\mathrm{C}-\mathrm{S}$ bonds by 514.5 num radiation. "As another example. 4-nitrobenzenethiol and 4-nitrobenzoic acid adsorbed on silver are converted in ambient conditions to 4 -aminobenzenethiol and 4-aminobenzoic acid. respectively. upon the irradiation of an $\mathrm{Ar}^{+}$laser $(514.5 \mathrm{~nm})$. $^{6.8}$ These molecules are found, however, not to undergo such reactions on a gold surface with visible light. ${ }^{9}$ This indicates that Ag substrates can act as moderate photoelectron emitters. In fact, the photoemission behavior of silver is known to be different in many aspects from that of other metals. $^{\text {ic }}$

Ever since the discovery of SERS phenomenon. SERS spectra from molecules on silver and gold substrates have been extensively studied. In contrast. copper substrate has received far less attention owing to its inherent instability towards oxidation. Given the potential applications of copper as an inexpensive raw material in the development of various nano- and optoelectronic devices, it is desired to explore the characteristics of any possible laser-induced photoreaction occurring on nanostnictured copper substrates. Recently. we found that the copper foil etched in a dilute solution of $\mathrm{HNO}_{3}$ is an efficient photoelectron emitter such that the SERS spectrum of 4 -nitrobenzenethiol on copper is readily converted to that of 4 -aminobenzenethiol under the $632.8 \mathrm{~mm}$ radiation from a He/Ne laser. ${ }^{\text {]l }}$ In this light, the SERS of bis(4-nitrophenyl) disulfide on copper has been investigated. The first concern of this investigation is whether $\mathrm{S}-\mathrm{S}$ bond scission will occur for bis(4-nitrophenyl) disulfide during self-assembly adsorption process on copper surface. The second concern is to determine whether the nitro group will also be converted to amine on copper substrate. In fact. the conversion of bis(4-nitrophenyl) disulfide to $t$-aminobenzenethiol by visible laser appeared to occur on copper. conforming again a remarkable photoelectron emitting characteristics of the nanostructured copper.

\section{Experimental}

Copper foil (0.05 mm thick), bis(t-nitrophenyl) disulfide, and 4 -aminobenzenethiol, were purchased from Aldrich and used as received. Unless otherwise specified, other chemicals were reagent grade. and a highly pure water of resistivity greater than $18.0 \mathrm{M} \Omega \cdot \mathrm{cm}$ (Millipore Milli-Q System) was used when making aqueous solutions. The $\mathrm{Cu}$ foil was made to be SERS-active by immersing it in diluted ( $1: 1) \mathrm{HNO}_{3}$ solution for $-30 \mathrm{~s}$. For the self-assenbly of bis(4-nitrophenyl) disulfide or t-antinobenzenethiol onto $\mathrm{Cu}$, the $\mathrm{HNO}_{\text {- }}$-etched $\mathrm{Cu}$ foil was immersed in $1 \mathrm{mM}$ ethanolic solution of the adsorbate for about $1 \mathrm{~h}$. The stock solutions of adsorbate in ethanol were bubbled with nitrogen before use

Raman spectra were obtained using a Renishaw Rantan system Model 2000 spectrometer equipped with an integral microscope (Olympus BH2-UMA). The $632.8 \mathrm{~nm}$ line from a $17 \mathrm{~mW} \mathrm{He} / \mathrm{Ne}$ laser (Spectra Ply sics Model 127) or the $\mathbf{5 1 4 . 5}$ nm line from a $20 \mathrm{~mW} \mathrm{Ar}{ }^{+}$laser (Spectra Physics Model 163-C 4210 ) were used as the excitation source. Raman scattering was detected with $180^{\circ}$ geometry with a Peltier cooled $\left(-70^{\circ} \mathrm{C}\right)$ charge-coupled device $(\mathrm{CCD})$ camera $(400 \times 600$ pixels). The laser bean was focused onto a spot approximately 1 $\mu \mathrm{m}$ in diameter with an objective microscope with magnification of the order of $20 \times$. The holographic grating (1800 grooves/ $/ \mathrm{mm}$ ) and the slit allowed the spectral resolution to be $1 \mathrm{~cm}^{-1}$. The Raman band of a silicon wafer at $520 \mathrm{~cm}^{-1}$ was used to calibrate the spectrometer.

\section{Results and Discussion}

Figure la and lo show the normal Raman spectrum of neat bis(4-nitrophenyl) disulfide and its SERS spectrum on copper substrate, respectively. both of which were obtained using a $\mathrm{He} / \mathrm{Ne}$ laser at $632.8 \mathrm{~nm}$ as an excitation source: the power at the sampling position was $\sim 1 \mathrm{~mW}$. These two spectra exhibit quite different spectral patterns with each other. Although a few peaks related to the benzene ring modes appear nearly at the same position, the complete absence of the S-S stretching peak in the SERS spectrum. weakly observable at $553 \mathrm{~cm}^{-1}$ for pure biș(4-nitrophenyl) disulfide (reported at $542 \mathrm{~cm}^{-1}$ for di- 


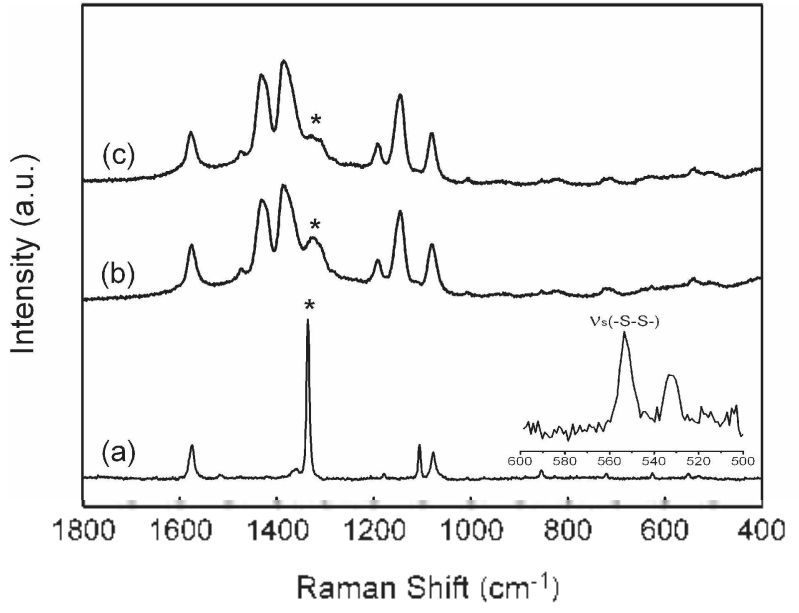

Figure I. (a) Nomal Raunan spectrum of bis(4-ritrophenyl) disul fide in neat solid state. SERS spectra of bis(4 nitrophenyl) disultide adsorbed on $\mathrm{HNO}_{\mathrm{i}}$ etched ( $\mathrm{Cu}$ (b) measured immediately and (c) after 5 min. All spectra were obtained using a Fe $\mathrm{Ne}$ laser at $632.8 \mathrm{~nm}$ as the excitation source. The stars $\left(^{*}\right)$ indicate the $v_{(}\left(\mathrm{NO}_{1}\right)$ neak. The irtset spectrum shows the $\mathrm{S} S \mathrm{~s}$ stretching peak of pure bis(4 nitrophenyl) disulfide.

phenyl disulfide ${ }^{12}$ ), indicates that bis(4-nitrophenyl) disulfide is adsorbed on Cu as thiolate alter the S-S bond cleavage. Sandroff and Herschbach ${ }^{12}$ used SERS to study diphenyl disulfide adsorbed onto Ag films and found that the $\mathrm{S}-\mathrm{S}$ bond cleaved under mild conditions. They cast a film of the disulfide onto an Ag film, and the STRS spectrum that they obtained was identical to that observed for the mercaptide on silver. From this observation they concluded that the disulfide adsorbs onto film as the monomer. More recently, Nolt $t^{\prime} \mathrm{at}^{1.3}$ compared the S-S bond dissociation energies of various disulfides by means of a density functional theory (IDF [) calculation. They found that the dissociation energy of diphenyl disulfide is lower $(-15 \mathrm{kcalimol})$ than that of dialkyl disulfide. The latter diflerence suggests that the S-S bond in diphenyl disulfide is much easier to cleave than that in dialkyl disullide during their seli-assembly onto metal substrates. Similarly, the S-S bond of bis(4-nitrophenyl) disulfide is assumed to cleave while adsorbing onto the copper surface.

In the Raman spectrum (Figure la), the predominant Raman peak at $1335 \mathrm{~cm}^{-1}$ can be assigned to the symmetric stretching vibration of the nitro group ( $\left.\mathrm{V}_{5}\left(\mathrm{NO}_{2}\right)\right)$ of bis(4-nitrophenyl) disulfide. In its SERS spectrum (Figure Ib), however, more enhanced peaks are observed around 1431,1388 , and 1140 $\mathrm{cm}^{-1}$. Interestingly, these bands can all be attributed to 4-aminobenzenethiol (vide infra). ${ }^{14}$ Their apparent enhancement has been ascribed in the literature to the charge-transler (CT) from metal to the adsorbed molecule. ${ }^{14-16}$ In particular in the potentia] dependent experiment, the intensity of the peak at $\sim 1430$ $\mathrm{cm}^{-1}$ varied as a function of the applied potential, in agreement with the CT mechanism, while the $\mathrm{C}-\mathrm{S}$ stretching band at $-1080 \mathrm{~cm}^{-1}$ was almost insensitive to the potential change since the band (a $a_{1}$-type) was enhanced only via the EM mechanism. Figure lc shows the SERS spectrum of bis(4nitrophenyl) disulfide adsorbed on $\mathrm{Cu}$ acquired after the exposure of the $\mathrm{He} / \mathrm{Ne}$ laser light for $5 \mathrm{~min}$. The stars (*) in Figure $\mathrm{l}$ indicate the $\mathrm{v}_{5}\left(\mathrm{NO}_{2}\right)$ peak. We noticed that upon

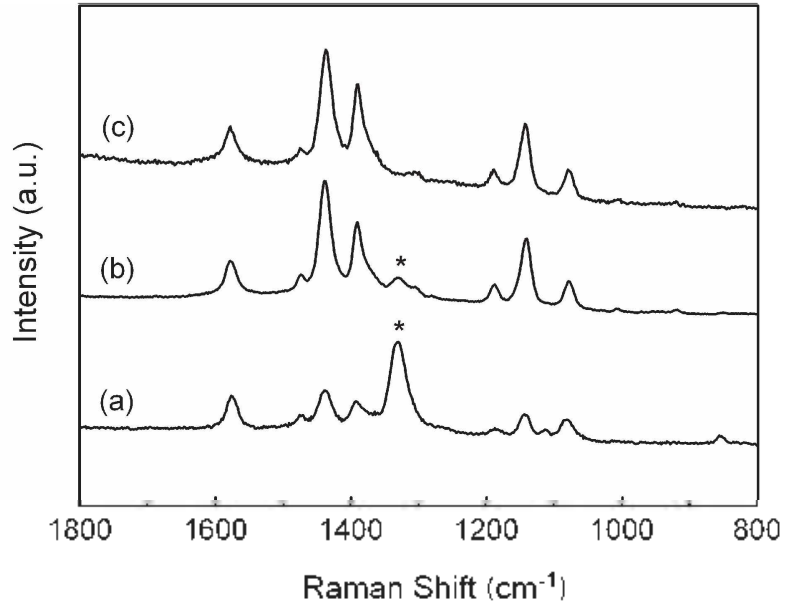

Figure 2. SERS spectra of bis(4 nitrophenyl) disulfide adsorbed on $\mathrm{H} . \mathrm{NO}_{3}$-etched $\mathrm{Cu}$ measured using (a) a slightly defocused and (b) a focused laser beam. (c) SI:RS spectrum of 4 -aminobenzenethiol adsorbed on IINO ${ }_{3}$ etched Cu for comparison. All spectra were obtained usitsg an $\mathrm{Ar}^{+}$laser at $514.5 \mathrm{~nm}$ as the excitation source. The stars (*) indicati the $v_{(}\left(\mathrm{NO}_{2}\right)$ peak.

increasing the irradiation time, the $v_{\mathrm{s}}\left(\mathrm{NO}_{2}\right)$ peak at $\cdots 1340 \mathrm{~cm}^{-1}$ gradually decreases.

[o gain more insight into the laser-induced photoreaction, the SERS spectra were also measured using the $514.5 \mathrm{~nm}$ radiation as the excitation source. The SERS spectrum shown in Figure 2 a was taken using a slightly defocused laser beam to minimize laser-induced changes, while the SERS spectrum of Figure 2b was taken using a focused laser beam at the same wavelength: the power at the sampling position was again $\sim$ l $\mathrm{mW}$. Any spectral change observable using the $514.5 \mathrm{~nm}$ radiation was much the same as that observed already by the 632.8 nm excitation. The SERS spectral pattern is obviously affected by the size of the laser beam. As indicated by the stars (*) in Figure 2, the $v_{5}\left(\mathrm{NO}_{2}\right)$ peak at $\sim 1340 \mathrm{~cm}^{-1}$ gradually decreases and several new peaks are emerging, for instance, at 1430,1387 , and $1144 \mathrm{~cm}^{-1}$, each of which can be assigned to the ring $19 \mathrm{~b}\left(\mathrm{v}_{\mathrm{CO}}+\delta_{\mathrm{CH}}\right), 3\left(\mathrm{vOC}_{\mathrm{C}} \delta_{\mathrm{CH}}\right)$, and $9 \mathrm{~b}\left(\delta_{\mathrm{CH}}\right)$ modes of 4-aninobenzenethiol, respectively (vide supra). ${ }^{14.17}$ The SERS spectrum of 4-aminobenzenethiol adsorbed on $\mathrm{HNO}_{3}$-etched $\mathrm{Cu}$ foil is also shown together in Figure $2 \mathrm{c}$ for comparison.

The overall processes of adsorption and conscculive laser-induced photoreaction of bis(4-nitrophenyl) disulfide on $\mathrm{Cu}$ surface are schematically drawn in Figure 3. Initially, bis(4-nitrophenyl) disulfide molecules adsorb on Cu as 4-nitrobenzenethiolates involving a facile cleavage of their S-S bonds. 4-Nitrobenzenethiolates on Cu are then subjected to laser-induced photoreaction to convert to 4-aminobenzenethiolates by either a Ie Ne laser at $632.8 \mathrm{~nm}$ or an $\Lambda \mathrm{r}$ ion laser at $514.5 \mathrm{~nm}$. The nitro-to-amine conversion is, in fact, a reductive reaction, necessitating photoelectrons. It is then remarkable that the $\mathrm{HNO}_{s}$-etched copper foil must be an efficient photoelectron emitter even under the $632.8 \mathrm{~nm}$ radiation. Recalling the carlier report that the surface roughening of silver not only causes a dramatic enhancement of photoyields at the wavelength close to the surface plasmon frequency but also leads to an extension of the photoresponse toward longer wavelengths, ${ }^{18}$ the present observation may not be unrealistic. 


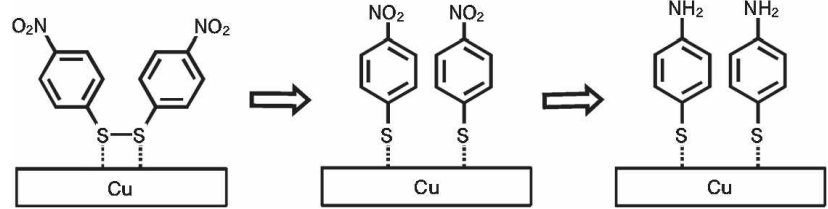

Figure 3. A schematic diagram showing the laser-induced photoreaction of bis(4-nitrophenyl) disulfide on Cu surface. Self-assembly adsorption process of bis(t-mitropheny l) disulfide and subsequent nitro to amine cons ersion on copper subsirate by visible laser during the StiRS measurements.

lt is nonetheless remarkable that the photoelectrons generated from an etched $\mathrm{Cu}$ substrate are more powerful than those from an Ag substrate at least under the irradiation of $632.8 \mathrm{~nm}$ radiation.

\section{Conclusions}

We have shown that the SERS spectrum of bis(4-nitrophenyl) disulfide on copper is readily converted to that of 4-aminobenzencthiol by the irradiation of either an Ar laser or a $\mathrm{He} / \mathrm{Ne}$ laser. 'That is, the disulfide adsorbate was adsorbed initially on copper as thiolate by the $\mathrm{S}-\mathrm{S}$ bond scission, and the nitro-to-amine conversion took place by the laser-induced photoreduction. The most remarkable observation was that the photoclectrons generated from an elched copper foil are more powerful than those from an Ay substrate at least under the irradiation of the $632.8 \mathrm{~nm}$ radiation. We accordingly expect that both the higher SERS activity and the noticeable photoelectron emission characteristics of the copper nanostructures are invaluable for the development of copper-based nano- and opto-electronic devices.
Acknowledgments. This work was supported by Soongsil University Research Fund.

\section{References}

I. Chang. R. K.: Furtak. T. E. Surface Finhonced Ranon S'somering: Plenum Press: New York. 1982.

2. Aroca. R. Sinface-finhonced Vibrationat Spectroscopy: Wilcy: Chichester. 2006 .

3. Shin. K. S.: Ryoo. H.: Lec. Y. M.: Kim. K. Bull, Korean (hen. Wisc. 2018. 29. 445

4. Cho. K. H.: Joo. S. W. Bull Korean (Them. Soc. 2008. 29. 69.

5. I.ce. I.: IJan. S. W.: Kim. C. H.: Kim. T. G.: Joo. S. W.: Jang. D.-J.: Kim. K. Langmir 2000. /6. 9963.

6. Han. H. S.: Han. S. W.: Kim. C. H.: Kim. K. Iongmuir 2000.16. 1149.

7. Han. S. W.: Lec. I.: Kinl. K. Iongmuir 2002. 18.182

8. Kim. K.: Lec. I.: Lee. S. J. Chem. Whr. Lett. 201)3. 377.201

9. Joo. S. W.: Han. S. W.: Kim. K. Appl Spectroxc. 20001. 54. 378.

I0. Fedurco. M.: Shklover. V.: Augusţ nski. J. J. Phus. (hem. B 1997. 101.5158

11. Shin. K. S.: Lec. H. S.: Joo. S. W.: Kim. K. I. Phys (hem. (' 2007. /1/. 15223.

12. Sandrofr. C. J.: Herschbach. D. R. J. Phy Chem 1982, \$6. 3277.

13. Noh. J.; Jang. S.: Lec. D.: Shin. S.; Ko. Y. J.: J10. E.: Joo. S.-W. (urr. Appl. Phas. 2007. 7. 6015.

14. Osawa. M.: Malsuda. V.: Yoshii. K.: Uchida I. J. Phan. Chem 1994. Ds. 12707

15. Zhu. Z.: Zhu. T : Liu. Z. Nontetechtology 2004. 15.357.

16. Baia. M.: Toderas. F.: Baia. L.: Popp. J.: Astilean. S. (hem. Phys Lett. 2006. +22. 127.

17. Varsanyi. G. Astignments for Vibrotional Sipectra of Soven Hundred Benzene Derivatinew: Wiley: New York. 1974.

18. Kim. C.W.: Villagran. J. C.: Even. U.: Thompson. J. C.J. Chem. Phys, 1991, 94. 3974. 